\title{
Germinação e vigor de sementes de chia (Salvia hispanica L. - Lamiaceae) sob diferentes temperaturas e condições de luz
}

STEFANELLO, R..; NEVES, L.A.S.'; ABBAD, M.A.B. ${ }^{1 ;}$ VIANA, B.B. ${ }^{1}$

1 Universidade Federal de Santa Maria (UFSM), Avenida Roraima, 1000, RS, Santa Maria, RS, Brasil, 97105-

900. *Autor para correspondência: raquelstefanello@yahoo.com.br

\begin{abstract}
RESUMO: A Salvia hispanica, conhecida popularmente como chia, apresenta elevada notabilidade por suas características nutricionais, sendo rica em proteínas, fibras, sais minerais e ácidos graxos, os quais podem ser responsáveis pela diminuição do risco de doenças cardiovasculares. Apesar do crescente consumo, existem poucos estudos em relação à germinação e ao vigor de suas sementes. Assim, o presente trabalho teve como objetivo avaliar os efeitos da luz e da temperatura no potencial fisiológico de sementes de chia (Salvia hispanica L.). Para tal, as sementes foram colocadas para germinar nas temperaturas constantes de 20 , 25 e $30^{\circ} \mathrm{C}$ na presença e ausência de luz. Os parâmetros avaliados foram: percentagem de germinação, primeira contagem, índice de velocidade de germinação, e comprimento e massa seca das plântulas. O delineamento experimental utilizado foi inteiramente casualizado com quatro repetições de 100 sementes. Constatou-se que a germinação das sementes de chia ocorre tanto na presença quanto na ausência de luz. As sementes de chia, sem dormência, germinam melhor na temperatura constante de $20^{\circ} \mathrm{C}$.
\end{abstract}

Palavras-chave: plantas medicinais, fotoblastismo, qualidade fisiológica.

\begin{abstract}
Germination and vigor of chia seeds (Salvia hispanica L. - Lamiaceae) under different temperatures and light conditions. The Salvia hispanica, known as chia, has high notability for its nutritional features, being rich in protein, fiber, minerals and fatty acids, which can be responsible for reducing the risk of cardiovascular diseases. Although the consumption of the seed is increasing, there are few studies about the germination and vigor of the seeds. The aim of this study was to evaluate the effects of light and temperature on the physiologic potentiality of chia seeds (Salvia hispanica L.). The seeds were sowed on paper at constant temperatures of 20,25 and $30^{\circ} \mathrm{C}$ in the presence or absence of light. The parameters evaluated were the following: percentage of germination, first count, germination speed index, length, and dry weight of the seedlings. The experimental design used was of complete randomized plots with four replications of 100 seeds. The germination of the chia seeds occurred in the presence or absence of light. The chia seeds, without dormancy, germinated better at the constant temperature of $20^{\circ} \mathrm{C}$.
\end{abstract}

Keywords: medicinal plants, photoblastism, quality physiological.

\section{INTRODUÇÃO}

A Salvia hispanica L., popularmente conhecida como chia, é uma planta cultivada através de sementes e apresenta uma considerável quantidade de antioxidantes, proteínas, fibra alimentar e ácidos graxos a-linolênico (SandovalOliveros \& Paredes-López, 2013).

Nos últimos anos essa semente tornouse importante para a alimentação por fornecer benefícios à saúde humana (Sandoval-Oliveros
\& Paredes-López, 2013), como, por exemplo, a redução de doenças cardiovasculares, colesterol, triglicerídeos, obesidade e regulação do intestino, bem como prevenção de doenças como a diabetes do tipo II e de alguns tipos de câncer (VázquezOvando et al., 2010; Ixtaina et al., 2011; Jin et al., 2012).

O processo germinativo na semente pode ser afetado por fatores internos, externos ou 
ambientais (Luz et al., 2014). A sensibilidade das sementes à luz é bastante variável de acordo com a espécie, havendo sementes cuja germinação é influenciada positiva ou negativamente pela luz e sementes indiferentes a esse fator, denominadas fotoblásticas positivas, negativas e neutras, respectivamente (Guedes \& Alves, 2011; Carvalho \& Nakagawa, 2012; Taiz \& Zeiger, 2013).

A temperatura, por outro lado, influencia tanto na percentagem quanto na velocidade de germinação, interferindo na absorção da água e nas reações bioquímicas (Carvalho \& Nakagawa, 2012). Vários estudos têm demonstrado que a luz e a temperatura interferem na germinação da semente de diferentes espécies, como Calendula officinalis (Koefender et al., 2009); Blephacoralyx salicifolius (Rego et al., 2009); Piper sp. (Bergo et al., 2010; Pacheco Junior et al., 2013); Stevia rebaudiana, Salvia sclarea e Tagetes minuta (Kumar \& Sharma, 2012); Ipomea grandifolia (Orzari et al., 2013); Digitaria insularis (Mendonça et al., 2014); Murdannia nudiflora (Luz et al., 2014), entre outros.

Apesar do aumento considerável de conhecimentos relativos à utilização de sementes de chia para fins medicinais e condimentares, as informações sobre o processo germinativo de sementes desta espécie ainda são escassas e insuficientes se comparadas com as espécies ornamentais e hortaliças. Esta espécie é merecedora de estudos, não apenas quanto à importância nutricional, como, também, quanto à avaliação da qualidade fisiológica de suas sementes a fim de fornecer conhecimento útil que permita a elucidação do seu processo germinativo e a possível substituição da importação de suas sementes. Desta forma, o presente trabalho teve como objetivo avaliar os efeitos da luz e da temperatura no potencial fisiológico de sementes de Salvia hispanica L.

\section{MATERIAL E MÉTODOS}

O trabalho experimental foi desenvolvido no Laboratório de Genética Vegetal, do Departamento de Biologia, Centro de Ciências Naturais e Exatas da Universidade Federal de Santa Maria (RS).

Foram utilizadas sementes de chia (Salvia hispanica L.), família Lamiaceae, adquiridas de uma empresa tradicional em produção e comercialização de sementes, localizada no município de Santa Cruz do Sul (RS).

Para a avaliação do efeito da luz e da temperatura sobre o potencial fisiológico, as sementes de chia foram submetidas à presença ou ausência de luz nas temperaturas constantes de 20, 25 e $30{ }^{\circ} \mathrm{C}$ (Menezes et al., 2004; Brasil, 2009; Koefender et al., 2009; Rego et al., 2011; Luz et al., 2014).
$\mathrm{Na}$ presença de luz, as sementes foram colocadas em câmara de germinação, com regime de $8 \mathrm{~h}$ de luz e $16 \mathrm{~h}$ sem luz. Na ausência de luz, as sementes foram semeadas em sala iluminada com filtro de segurança formado por três folhas de papel celofane verde e mantidas no escuro durante todo o teste, cobrindo-se as caixas plásticas de germinação com duas folhas de papel alumínio (Stefanello et al., 2006). A condição com iluminação foi obtida nas câmaras de germinação pela utilização de quatro lâmpadas fluorescentes do tipo luz do dia $20 \mathrm{~W}$, com densidade de fluxo radiante na altura das caixas de $15 \mathrm{mmol} . \mathrm{m}^{-2} \cdot \mathrm{s}^{-1}$ (Koefender et al., 2009).

O potencial fisiológico das sementes foi avaliado através dos seguintes testes:

Teste de germinação (\%): realizado com quatro repetições de 100 sementes, distribuídas em caixas plásticas (gerbox), sobre três folhas de papel filtro umedecidas com água destilada na proporção de 2,5 vezes o peso do papel. Após a semeadura, as caixas plásticas (gerbox) foram mantidas nas temperaturas de 20,25 e $30^{\circ} \mathrm{C}$, sendo as contagens realizadas aos 7 e 14 dias (quando foi finalizado o teste). Os resultados foram expressos em percentagem de plântulas normais (Brasil, 2009).

Primeira contagem (\%): realizada juntamente com o teste de germinação, em que se determinou a percentagem de plântulas normais no sétimo dia após a instalação do teste (Brasil, 2009).

Índice de velocidade de germinação (IVG): as contagens das sementes germinadas foram efetuadas diariamente, no mesmo horário. $O$ critério de germinação foi a protrusão radicular. $\mathrm{O}$ índice de velocidade de germinação foi calculado empregando-se a fórmula de Maguire (1962):

$I V G=G_{1} / N_{1}+G_{2} / N_{2}+\ldots=G_{n} / N_{n}$

Onde:

IVG = índice de velocidade de germinação.

$\mathrm{G}_{1}, \mathrm{G}_{2}, \mathrm{G}_{\mathrm{n}}=$ número de sementes germinadas computadas na primeira contagem, na segunda contagem e na última contagem.

$\mathrm{N}_{1}, \mathrm{~N}_{2}, \mathrm{~N}_{\mathrm{n}}=$ número de dias da semeadura à primeira, segunda e à última contagem.

Comprimento das plântulas $(\mathrm{cm})$ : as plântulas normais foram obtidas a partir da semeadura de quatro repetições de 20 sementes. Os rolos de papel contendo as sementes permaneceram em câmara de germinação por sete dias, à temperatura de 20,25 e $30^{\circ} \mathrm{C}$, quando então, foi avaliado, aleatoriamente, o comprimento total de 10 plântulas em cada repetição, com o auxílio de uma régua milimetrada. $\mathrm{O}$ comprimento médio das plântulas foi obtido somando-se as medidas de cada repetição e dividindo-se pelo número de plântulas normais mensuradas, com resultados expressos em cm. plântula-1. 
Massa seca das plântulas (mg): determinada, primeiramente, através da obtenção do peso fresco das 10 plântulas previamente medidas, nas quatro repetições e mantidas em sacos de papel, em estufa com temperatura de $60{ }^{\circ} \mathrm{C}$, até a obtenção de massa constante (48 h). Posteriormente, as plântulas foram novamente pesadas em balança de precisão, com resolução de $0,001 \mathrm{~g}$, sendo os resultados expressos em mg.plântula-1.

O delineamento experimental utilizado foi o inteiramente casualizado, onde os tratamentos constituíram um fatorial $3 \times 2$ (3 temperaturas $x$ presença ou ausência de luz). As variáveis germinação e primeira contagem foram transformadas em arc sen $\sqrt{x / 100}$. Para análise da variância empregou-se o teste $\mathrm{F}$ e, quando este foi significativo, as comparações entre as médias dos tratamentos foram efetuadas pelo teste de Scott Knott, ao nível de $5 \%$ de probabilidade. Para a análise dos dados foi utilizado o programa estatístico SISVAR (Ferreira, 2000).

\section{RESULTADOS E DISCUSSÃO}

A plântula normal e a anormalidade mais frequente nas plântulas de chia (Salvia hispanica) estão apresentadas na Figura 1. De acordo com Brasil (2009), as plântulas normais são aquelas que apresentam estruturas essenciais como sistema radicular e parte aérea (hipocótilo, epicótilo, gemas terminais, cotilédone) e mostram potencial para continuar seu desenvolvimento, dando origem a plantas normais quando submetidas a condições favoráveis. Por outro lado, as plântulas anormais são aquelas com qualquer uma das suas estruturas essenciais ausentes e que não apresentam potencial para continuar seu desenvolvimento e dar origem a plantas normais, mesmo crescendo em condições favoráveis.

Através da análise dos dados de germinação, primeira contagem, índice de velocidade de germinação de sementes e massa seca de plântulas de Salvia hispanica, observou-se que não houve diferença significativa nas duas condições de luz utilizadas. Assim, os resultados são apresentados indicando, para cada um dos testes (exceto comprimento das plântulas), somente as diferenças observadas entre as temperaturas.

Observa-se que as sementes apresentaram comportamento indiferente à luz (Tabelas 1, 2 e 3). Essa espécie, provavelmente, apresenta a forma de fitocromo fiA, que controla a germinação através da resposta de fluência muito baixa (Takaki, 2005) ou pode ser classificada como indiferente à luz ou fotoblástica neutra, uma vez que germina independente do regime de luz (Guedes \& Alves, 2011; Carvalho \& Nakagawa, 2012; Orzari et al., 2013; Taiz \& Zeiger, 2013).

Em relação à temperatura, nos testes de germinação e de primeira contagem observou-se que os maiores percentuais de plântulas normais foram obtidos na temperatura de $20^{\circ} \mathrm{C}$ (Tabela 1). Resultados semelhantes foram obtidos na germinação de sementes de Salvia splendens (Menezes et al., 2004), calêndula - Calendula officinalis (Koefender et al., 2009), alfavaca Ocimum selloi (Costa et al., 2010) e corda-de-viola - Ipomoea grandifolia (Orzari et al., 2013).

$\mathrm{Na}$ temperatura de $30{ }^{\circ} \mathrm{C}$, a maioria das plântulas obtidas foram anormais apresentando a raiz primária pouco desenvolvida, epicótilo curto e necrosado (Figura 1B). As temperaturas mais altas tendem a estimular a germinação; mas, a partir de um determinado ponto, o efeito da temperatura se
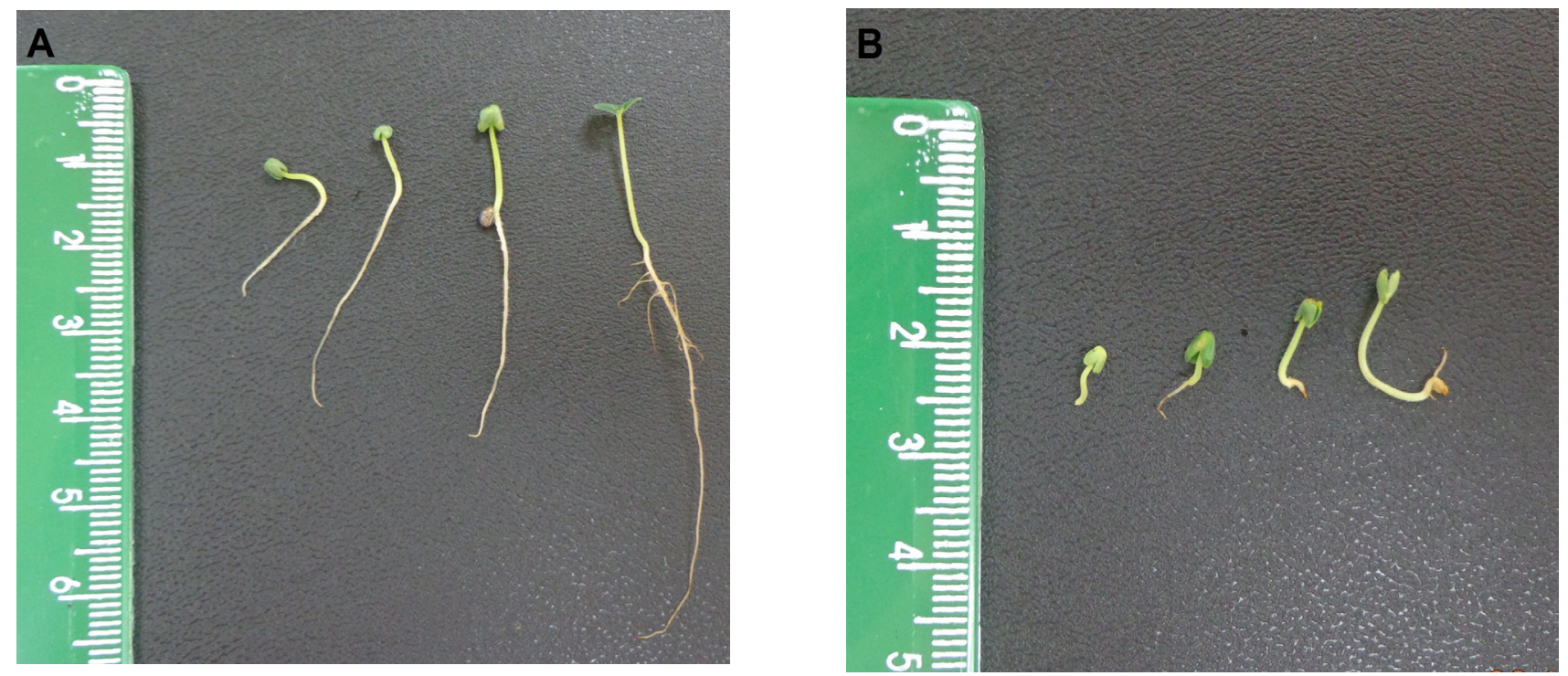

FIGURA 1. Plântulas normais (A) e anormais (B) de Salvia hispanica (chia).

Rev. Bras. PI. Med., Campinas, v.17, n.4, supl. III, p.1182-1186, 2015. 
TABELA 1. Germinação (\%) e primeira contagem de germinação (\%) de sementes de chia (Salvia hispanica L.), submetidas a diferentes temperaturas na presença e ausência de luz.

\begin{tabular}{|c|c|c|c|c|}
\hline \multirow{2}{*}{ Temperatura } & \multicolumn{2}{|c|}{ Germinação (\%) } & \multicolumn{2}{|c|}{ Primeira contagem (\%) } \\
\hline & Presença de luz & Ausência de luz & Presença de luz & Ausência de luz \\
\hline $20^{\circ} \mathrm{C}$ & $88 a^{*}$ & $87 \mathrm{a}$ & $81 \mathrm{a}$ & $83 a$ \\
\hline $25^{\circ} \mathrm{C}$ & $77 \mathrm{~b}$ & $79 \mathrm{~b}$ & $73 \mathrm{~b}$ & $72 \mathrm{~b}$ \\
\hline $30^{\circ} \mathrm{C}$ & $74 \mathrm{~b}$ & $73 \mathrm{c}$ & $72 \mathrm{~b}$ & $72 \mathrm{~b}$ \\
\hline
\end{tabular}

* Médias, seguidas de mesma letra minúscula, em cada coluna, não diferem entre si, pelo teste de Scott Knott, a 5\% de probabilidade.

inverte e a germinação começa a cair, até que o ponto da temperatura máxima é atingido, a partir do qual nenhuma semente mais germina (Carvalho \& Nakagawa, 2012). As altas temperaturas podem, portanto, ter efeitos prejudiciais sobre a germinação de sementes (Oliveira et al., 2014), como observado neste trabalho.

Em relação ao índice de velocidade de germinação (IVG) de Salvia hispanica, observouse que não houve influência significativa da luz e da temperatura (Tabela 2). Segundo Carvalho \& Nakagawa (2012), a temperatura ótima para a germinação total é diferente da ótima para a velocidade de germinação das sementes. Estes autores ressaltam que em temperaturas mais elevadas a velocidade de absorção de água e das reações químicas é maior, o que justifica as sementes germinarem mais rapidamente e, assim, não serem observadas diferenças na velocidade de germinação nas temperaturas testadas.

Em relação ao comprimento das plântulas de chia verificou-se, através da análise da variância,

TABELA 2. Índice de velocidade de germinação (IVG) de sementes de chia (Salvia hispanica L.), submetidas a diferentes temperaturas na presença e na ausência de luz.

\begin{tabular}{ccc}
\hline Temperatura & $\begin{array}{c}\text { Presença } \\
\text { de luz }\end{array}$ & $\begin{array}{c}\text { Ausência } \\
\text { de luz }\end{array}$ \\
\hline $20^{\circ} \mathrm{C}$ & $81 \mathrm{a}^{*}$ & $79 \mathrm{a}$ \\
$25^{\circ} \mathrm{C}$ & $79 \mathrm{a}$ & $75 \mathrm{a}$ \\
$30^{\circ} \mathrm{C}$ & $80 \mathrm{a}$ & $77 \mathrm{a}$ \\
\hline
\end{tabular}

* Médias, seguidas de mesma letra minúscula, em cada coluna, não diferem entre si, pelo teste de Scott Knott, a 5\% de probabilidade. que houve interação significativa entre os fatores analisados. Os maiores comprimentos das plântulas foram observados em presença de luz na temperatura de $25^{\circ} \mathrm{C}(10,21 \mathrm{~cm})$, sendo que na ausência de luz não foram observadas diferenças no comprimento $(9,48 ; 9,51$ e $9,11 \mathrm{~cm})$ nas temperaturas de 20, 25 e $30^{\circ} \mathrm{C}$, respectivamente (Tabela 3 ).

Em relação à massa seca, não houve efeito dos tratamentos (ausência e presença de luz), em todas as temperaturas testadas (Tabela 3). Para sementes de Salvia splendens Sellow, os maiores conteúdos de massa seca foram obtidos na temperatura de $20^{\circ} \mathrm{C}$ sob regime de luz branca (Menezes et al., 2004), no entanto, a luz não influenciou o conteúdo de massa seca das plântulas de Bowdichia virgilioides Kunth (Albuquerque \& Guimarães, 2007).

Contudo, é importante enfatizar que a busca de conhecimentos sobre as condições ótimas para a germinação das sementes e para o desenvolvimento inicial das plantas, desempenha papel fundamental dentro da pesquisa científica e fornece informações valiosas sobre a propagação das espécies. Desta forma, são necessários mais estudos para elucidar estas relações visando à produção de sementes de qualidade (requisito essencial para o sucesso de qualquer cultura) e a preservação desta espécie que possui reconhecida importância para a saúde humana.

Como conclusão, pode-se afirmar que a germinação de sementes de chia (Salvia hispanica L.) ocorre tanto na presença quanto na ausência de luz. As sementes de chia (Salvia hispanica L.) germinam melhor na temperatura constante de $20^{\circ} \mathrm{C}$. A temperatura de $30^{\circ} \mathrm{C}$ não é adequada para a germinação das sementes de chia (Salvia hispanica L.).

TABELA 3. Comprimento $(\mathrm{cm})$ e massa seca $(\mathrm{mg})$ das plântulas de chia (Salvia hispanica L.), submetidas a diferentes temperaturas na presença e na ausência de luz.

\begin{tabular}{lcccc}
\hline \multirow{2}{*}{ Temperatura } & \multicolumn{2}{c}{ Comprimento das plântulas $(\mathrm{cm})$} & \multicolumn{2}{c}{ Massa seca das plântulas (mg) } \\
\cline { 2 - 5 } & Presença de luz & Ausência de luz & Presença de luz & Ausência de luz \\
\hline $20{ }^{\circ} \mathrm{C}$ & $9,14 \mathrm{~b} \mathrm{~A}^{*}$ & 9,48 a A & 0,65 a A & 0,52 a A \\
$25^{\circ} \mathrm{C}$ & 10,21 a A & 9,51 a B & 0,65 a A & 0,62 a A \\
$30{ }^{\circ} \mathrm{C}$ & 7,57 c B & 9,11 a A & 0,57 a A & 0,62 a A \\
\hline
\end{tabular}

* Médias, seguidas de mesma letra minúscula, em cada coluna, e letra maiúscula, em cada linha, não diferem entre si, pelo teste de Scott Knott, a $5 \%$ de probabilidade.

Rev. Bras. PI. Med., Campinas, v.17, n.4, supl. III, p.1182-1186, 2015. 


\section{REFERÊNCIAS}

ALBUQUERQUE, K.S.; GUIMARÃES, R.M. Comportamento fisiológico de sementes de Bowdichia virgilioides Kunth sob diferentes temperaturas e condições de luz. Cerne, v. 13, n. 01, p. 64-70, 2007.

BERGO, C.L.; et al., Luz e temperatura na germinação de sementes de pimenta longa (Piper hispidinervum) e pimenta-de-macaco (Piper aduncum). Revista Brasileira de Sementes, v. 32, n 3, p. 170-176, 2010.

BRASIL. Ministério da Agricultura, Pecuária e Abastecimento. Regras para análise de sementes. Secretaria de Defesa Agropecuária. Brasília: Mapa/ ACS, 2009. 399p.

CARVALHO, N.M.; NAKAGAWA, J. Sementes: ciência, tecnologia e produção. 5 ed. Jaboticabal: Funep, 2012. 590p.

COSTA, L.C. B. et al., Qualidade fisiológica de sementes de Ocimum selloi Benth sob condições de luz, temperatura e tempo de armazenamento. Ciência e Agrotecnologia, v. 34, n. 3, p. 675-680, 2010.

FERREIRA, D.F. Manual do sistema Sisvar para análises estatísticas. Lavras: UFLA, 2000. 69p.

GUEDES, R.S.; ALVES, E.U. Substratos e temperaturas para o teste de germinação de sementes de Chorisia glaziovii (O. Kuntze). Cerne, v. 17, n. 4, p. 525-531, 2011.

IXTAINA, V.Y. et al., Characterization of chia seed oils obtained by pressing and solvent extraction. Journal of Food Composition and Analysis, v. 24, n. 2, p.166174, 2011.

JIN, F.; et al., Supplementation of milled chia seeds increases plasma ALA and EPA in postmenopausal women. Plant Foods for Human Nutrition. v. 67, p.105-110, 2012.

KOEFENDER, J.; et al., Influência da temperatura e da luz na germinação da semente de calêndula. Horticultura Brasileira, v. 27, p. 207-210, 2009.

KUMAR, R.; SHARMA, S. Effect of light and temperature on seed germination of important medicinal and aromatic plants in north western Himalaya. International Journal of Medicinal and Aromatic Plants, v. 2, n. 3, p. 468475, 2012.

LUZ, F.N.; et al.,. Interferência de luz, temperatura, profundidade de semeadura e palhada na germinação e emergência de Murdannia nudiflora. Comunicata Scientiae, v. 5, n. 1, p. 26-33, 2014.

MAGUIRE, J.D. Speed of germination-aid in selection and evaluation for seedling emergence and vigor. Crop Science, v. 2, n. 2, p. 176-177, 1962.

MENEZES, N.L, et al., Germinação de sementes de Salvia splendens Sellow em diferentes temperaturas e qualidade de luz. Revista Brasileira de Sementes, v. 26, n. 1, p. 32-37, 2004.

MENDONÇA, G.S. et al., Ecophysiology of seed germination in Digitaria insularis L. (Fedde). Revista Ciência Agronômica, v. 45, n. 4, p. 823-832, 2014.

OLIVEIRA, S.S.C. et al., Seleção de progênies de naboforrageiro para germinação sob altas temperaturas. Ciência Rural, v. 44, n. 2, p. 217-222, 2014.

ORZARI, I et al., Germinação de espécies da família Convolvulaceae sob diferentes condições de luz, temperatura e profundidade de semeadura. Planta Daninha, v. 31, n. 1, p. 53-61, 2013.

PACHECO JUNIOR, F, et al., Germination and vigor of long-pepper seeds (Piper hispidinervum) as a function of temperature and light. Revista Ciência Agronômica, v. 44, n. 2, p. 325-333, 2013.

REGO, S.S. et al., Germinação de sementes de Blephacoralyx salicifolius (H. B. K.) Berg. em diferentes substratos e condições de temperatura, luz e umidade. Revista Brasileira de Sementes, v. 31, n. 2, p. 212220, 2009.

SANDOVAL-OLIVEROS, M.R.; PAREDES-LÓPES, O. Isolation and characterization of proteins from chia seeds (Salvia hispanica L.). Journal of Agricultural and Food Chemistry, v. 61, p. 193-201, 2013.

STEFANELLO, R. et al., Influência da luz, temperatura e estresse hídrico na germinação e no vigor de sementes de anis. Revista Brasileira de Agrociência, v. 12, n. 1, p. 45-50, 2006.

TAIZ, L.; ZEIGER, E. Fisiologia vegetal. 5 ed. Porto Alegre: Artimed, 2013. 954p.

TAKAKI, M. A luz como fator de estresse na germinação de sementes. In: Nogueira, R.M.C. (Eds.). Estresses ambientais: danos e benefícios em plantas. Recife: UFRP, 2005, p. 243-248.

VÁZQUEZ-OVANDO, J.A. et al., Dry processing of chia (Salvia hispanica L.) flour: chemical characterization of fiber and protein. Journal of Food, v. 8, p. 117-127, 2010.

Rev. Bras. PI. Med., Campinas, v.17, n.4, supl. III, p.1182-1186, 2015. 